\title{
Saudi Undergraduate Computing Programs in Light of the 2020 Curricula Report
}

\author{
Yazeed Alabdulkarim ${ }^{1 *}$, Mohammed Almukaynizi ${ }^{*}{ }^{*}$, Marwan Almaymoni², \\ Abdulaziz Alhadlag ${ }^{1}$, Shada Alsalamah ${ }^{1}$, and Hessah Alsalamah ${ }^{1,3}$, \\ ${ }^{1}$ Information Systems Department, King Saud University, Riyadh, Saudi Arabia \\ ${ }^{2}$ Computer Science Department, King Saud University, Riyadh, Saudi Arabia \\ ${ }^{3}$ Computer Engineering Department, AlYamamah University, Riyadh, Saudi Arabia \\ Email: \{yalabdulkarim,malmukaynizi,maymoni,aalhadlag,saalsalamah,halsalamah\}@ksu.edu.sa
}

Received: April 26, 2021. Revised: July 12, 2021. Accepted: July 15, 2021. Published: July 19, 2021.

\begin{abstract}
University undergraduate programs in computing disciplines are updated regularly to adapt to advancements in the field and emerging, fast-growing industry demand. This paper reports the current status of a selected set of undergraduate programs in computing fields in Saudi Arabia and compares them to other programs from international universities in light of the 2020 Computing Curricula Report (CCR). This comparative study aims to enlighten future efforts for designing curricula and updating undergraduate computing programs in Saudi Arabia. A sample of 26 Saudi universities (15 public and 11 private) and 15 international universities offering 161 programs is selected. The comparison criteria include program discipline, duration, number of units, accreditation, required training, and others. We find significant differences between programs offered by Saudi public and private universities compared to international university programs. For example, programs offered by Saudi universities, especially the public, require more units compared to international programs (median of 143 units vs. 120 units). Our findings would guide future undergraduate computing program developments in Saudi Arabia.
\end{abstract}

Keywords- Computing disciplines; Undergraduate programs; Saudi universities

\section{INTRODUCTION}

Technological competitiveness and emerging technologies are more necessary in the organizational strategy to maximize efficiency and profitability as well as cope with business advances and improve the nation's economy 1. Furthermore, it is vital for businesses to keep informed of emerging technologies in the same way that they must remain vigilant of changes in consumer demands. This rapid change in technologies and business requirements are reflected in the profound advances in the field of computing. Consequently, academic institutions should offer programs that evolve to keep pace with these changes, attracting and graduating qualified students. For instance, back in 2005, the Computing Curricula Report (CCR) 2] reflected the need for such change back then by introducing Information Technology (IT), among other changes, as a new computing discipline for undergraduate programs. Similarly but more recently in 2017 and 2020, Cybersecurity and Data Science have emerged CCRs [3, respectively, to cope with the wave of interest and reflect that need for change in the marketplace. Currently, undergraduate computing programs offered by Saudi Arabian academic institutions are experiencing a surge in course enrollments, which is straining program resources at many academic institutions in Saudi Arabia and causing concern among faculty and administrators about how best to respond to the rapidly growing demand. There is also significant interest about what this growth will mean for the future of computing programs, and the role of the different computing specialties in academic institutions, the field as a whole, and Saudi Arabian society more broadly. Various studies in the literature were found aiming to differentiate between the computing specialties. Very limited studies in the literature looked at the specific specialities within the field of computing, rather the majority focuses on the skill sets within computing as ways to increase the student success and retention and meet the job market needs. This is without linking such skill sets with programs that can be introduced or expanded by educational institutes. Although such studies are crucial to help gain a better understanding of the skill sets needed in the field of computing in general, such articles, however, fail to provide a comprehensive study to help gain clarity on the various specialities in Saudi academic institutes' undergraduate programs at a granular level, 
see Section V. for details. This shortage limits educational institutes from strategically planning to expand their undergraduate programs to build the needed capabilities and skill sets to meet the job market. This, however, would widen the gap between academia and the job market leading to unemployment. Therefore, the study conducted in this article bridges this gap and overcomes the shortage in the literature by, first, comparing bachelor degree programs offered by public and private universities in Saudi Arabia. Second, shedding light on the major differences between these programs and some reputable international universities. Finally, assessing whether related courses are offered in these programs to fulfill the needs of Saudi Arabia as a country and a nation [4. In particular, this paper tries to answer the following questions:

1) How do undergraduate computing programs offered by Saudi public and private universities compare?

2) How do undergraduate computing programs offered by Saudi universities compare with computing programs offered by international universities?

3) How do the disciplines of undergraduate computing programs offered by Saudi universities match with the newly proposed disciplines of the 2020 CCR?

The answers provided in this article should uncover key differences in the curricula of the studied program to enlighten future efforts for designing curricula that both emphasize relevant scientific theory and best satisfy industry demand. This would equip educational institutes to expand their programs to build the needed capabilities and skill sets to meet the job market. The remainder of this paper is organized as follows. Section II. provides essential background information about various computing disciplines. Section III. explains the methodology of this study, while the analysis and discussion of the results are presented in Section IV. Related and future work are discussed in Section V. and Section VI. respectively.

\section{Computing Disciplines}

In academia, the term computing is often used to capture all disciplines that focus on the scientific-oriented study of computers. One may define computing as "any goal-oriented activity requiring, benefiting from, or creating computers" 2]. Before studying university programs, we review the recognized undergraduate degree programs in various computing disciplines. The Association for Computing Machinery (ACM), IEEE Computer Society (IEEE-CS) and others list seven computing disciplines for undergraduate degree programs in their 2020 CCR [3]. These disciplines are Computer Engineering, Computer Science, Information Systems, Information Technology, Software Engineering, Cybersecurity, and Data Science. We describe below these seven disciplines and discuss their commonalities and differences [2, 3], providing sufficient background to understand various undergraduate computing programs offered in Saudi Arabia.

\section{A- Computer Engineering (CE)}

$\mathrm{CE}$ joins computing and electrical engineering to prepare graduates to design and build computers and computer-based systems. It includes the study of hardware, software, and communications. It enables graduates to design circuits, computer and networking hardware components.

\section{B- Computer Science (CS)}

CS covers the theoretical foundations of computing with the focus on programming and software development. Significant number of CS curriculum hours is allocated to algorithms and complexity, programming languages, software development fundamentals, and software engineering.

\section{C- Information Systems (IS)}

IS focuses on information and its various tasks, including collecting, processing, analysis and storage of information. Moreover, it covers organizational aspects of building information systems. IS discipline requires both technical and business skills to harness computing capabilities to serve business needs and enable transformative change within organizations in various domains. IS programs may be offered in computing or business schools. IS programs offered in computing schools emphasize on technical skills while IS programs offered in business schools emphasize on managerial skills, covering organizational and behavioral aspects of IS.

\section{D- Information Technology (IT)}

IT focuses on technology to serve the needs of business and various types of organizations. It provides knowledge and practical aspects, preparing graduates for various IT tasks, such as selecting hardware and software products, installing, customizing and maintaining applications. Moreover, responsibilities of IT graduates may include installing networks, designing web pages and managing systems.

\section{E- Software Engineering (SE)}

$\mathrm{SE}$ is an engineering discipline that focuses on developing and maintaining software. SE emphasizes on using best development practices and designing software, with strong focus on quality, usability, reliability and security requirements. CS and SE programs are expected to share common courses related to software development.

\section{F- Cybersecurity (CSEC)}

CSEC is an interdisciplinary field covering security in several aspects, including data, software, component, connection, system, human, organizational and societal. CSEC requires both technical skills for areas, such as cryptography and network defense, and managerial skills for areas, such as policy and compliance. 


\section{G- Data Science (DS)}

DS is a new discipline that is related to data analytics. It is a multidisciplinary field, covering knowledge areas in computing, mathematics, statistics and business domains [5]. It focuses on extracting knowledge from data using several data-related tasks, such as acquisition, storage, management, analysis, and visualization.

These seven computing disciplines have their commonality and differences. For instance, CS has a strong theoretical focus. It provides computing foundations that are necessary, at different levels, for other computing disciplines. CE heavily focuses on hardware while covering limited aspects related to software. The area of software is related mostly to CS, SE, and IT. SE is unique in its focus on designing and developing software. IT focuses on technology which involves selecting and developing software and hardware solutions to serve organizational needs. The goal of satisfying organizational needs is most emphasized by IT, IS, and DS. IS is unique in its focus on information and understanding of business aspects to enable transformative change within organizations. DS shares that goal with IS to enable digital intelligence and transformation by focusing on data and extracting knowledge. DS covers knowledge areas across various disciplines, including mathematics, statistics, and business. Last, CSEC primarily focuses on security, which is an important aspect in all areas of computing.

To summarize and compare these computing disciplines, we use the six main knowledge areas identified in the 2020 CCR [3]. These knowledge areas are hardware, software fundamentals, software development, systems Architecture and infrastructure, systems modeling, and users and organizations. Each of these areas has different relative importance to the above computing disciplines, as shown in Figure 1. For example, it is clear that CE focuses on the knowledge area of hardware. In contrast, IS focuses on systems modeling, and users and organizations.

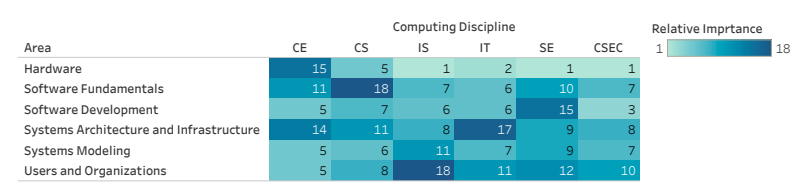

Fig. 1: Relative importance of different knowledge areas across computing disciplines 3 .

\section{Methodology}

For the purpose of this paper, we study 26 Saudi universities (15 public and 11 private), and 15 international universities, offering a total of 161 programs. The selection process is as follows. Selecting a sample of Saudi public universities is less straightforward as reputable rankings of computing schools involve a limited number of Saudi universities. For instance, the 2020 Shanghai subject ranking for computer science and engineering lists only three Saudi universities, which are King Abdulaziz University, King Abdullah University of Science and Technology (KAUST), and King Saud University [ 6 . Yet, KAUST does not offer undergraduate programs in computing, which is the focus of this study. As a result, we select the 15 oldest public universities in Saudi Arabia, see Table 2a. These universities cover 9 of the 13 provinces in Saudi Arabia. For the private sector, there are only 11 universities which offer undergraduate programs in computing, all of them are selected, see Table 2b,

To compare with international universities, the top 15 universities are selected based on the 2020 Shanghai subject ranking for computer science and engineering [ 6 , see Table 21 The list includes universities from five countries, such as the United States, United Kingdom and Australia, representing a variety of educational systems.

Information in this study is gathered from university websites, which typically list programs that are offered and provide details about these programs. Such details often include information such as program specialized tracks (or concentrations), admission requirements, program curriculum, accreditation agency names, etc. This paper considers each track as a standalone program to recognize its specialty. These programs are compared based on several criteria, such as program discipline and accreditation status, see Table 3 for details. Moreover, this study assesses if programs offer courses in AI and Security as these fields are attracting attention in Saudi Arabia and have high demands to fulfill the needs of the country $[7,8,9,4$. The second column of Table 3 provides a brief description for each comparison criterion. We provide necessary details about some of them as follows:

\section{- Program Discipline}

We classify each program based on the seven computing disciplines described in Section II. A program is classified into a specific computing discipline if its name or specialized track is the same as that computing discipline. If the program name and specialized track represent two different computing disciplines, the program is classified as Mixed. For example, King Saud University offers a program in Information Technology with specialization in Data Science, which is classified as a mixed program. However, if the program name and specialized track are not the same as any of the seven computing disciplines, it is classified as Others. For example, the University of Prince Mugrin, offers a program in Artificial Intelligence which is classified as others.

\section{- Number of Units}

The number of required units to earn a degree is

${ }^{1}$ ETH Zurich and Tsinghua University are replaced by the University of Texas at Austin and University of North Carolina at Chapel Hill, respectively, because their program information is not provided in English. 
Table 1: List of selected Saudi universities

\begin{tabular}{|l|}
\hline King Saud University \\
\hline King Abdulaziz University \\
\hline $\begin{array}{l}\text { King Fahd University of Petroleum } \\
\text { and Minerals }\end{array}$ \\
\hline Imam Muhammad Ibn Saud Islamic \\
University \\
\hline Imam Abdulrahman Bin Faisal \\
University \\
\hline King Faisal University \\
\hline Umm Al-Qura University \\
\hline King Khalid University \\
\hline Taibah University \\
\hline Taif University \\
\hline Qassim University \\
\hline Yanbu University College \\
\hline Jouf University \\
\hline Jazan University \\
\hline Al-Baha University \\
\hline
\end{tabular}

(a) Public Universities

Table 2: List of selected international universities

\begin{tabular}{|l|l|}
\hline University Name & Country \\
\hline $\begin{array}{l}\text { Tassachusetts Institute of } \\
\text { Stanford University }\end{array}$ & United States \\
\hline $\begin{array}{l}\text { University of California, } \\
\text { Berkeley }\end{array}$ & United States \\
\hline Carnegie Mellon University & United States \\
\hline Harvard University & United States \\
\hline $\begin{array}{l}\text { Nanyang Technological } \\
\text { University }\end{array}$ & Singapore \\
\hline University of Toronto & Canda \\
\hline University of Oxford & United \\
\hline $\begin{array}{l}\text { University of California, Los } \\
\text { Angeles }\end{array}$ & United States \\
\hline Princeton University & United States \\
\hline $\begin{array}{l}\text { University of Technology } \\
\text { Sydney }\end{array}$ & Australia \\
\hline Cornell University & United States \\
\hline $\begin{array}{l}\text { University of Southern } \\
\text { California }\end{array}$ & United States \\
\hline University of Texas at Austin & United States \\
\hline $\begin{array}{l}\text { University of North Carolina at } \\
\text { Chapel Hill }\end{array}$ & United States \\
\hline
\end{tabular}

computed differently across various educational systems, making them incomparable [10]. Universities in the United States follow the American Academic Credit System, on a semester or quarter basis. In contrast, European universities follow the European Credit Transfer and Accumulation System (ECTS). All Saudi universities follow the American Academic Credit System on semester basis. Consequently, this

\begin{tabular}{|l|}
\hline Prince Sultan University \\
\hline Effat University \\
\hline Dar Al-Hekma University \\
\hline Arab Open University \\
\hline Fahd bin Sultan University \\
\hline Mustaqbal University \\
\hline Al-Yamamah University \\
\hline Prince Mohammad Bin Fahd University \\
\hline Alfaisal University \\
\hline Almaarefa University \\
\hline University of Prince Mugrin \\
\hline
\end{tabular}

(b) Private Universities

study gathers the number of units for international universities following the same system to compare them with Saudi universities.

\section{- Number of Electives}

Electives are courses that are selected based on the preference of students. For the purpose of this study, we only consider computing electives and not free electives. Computing electives are courses that are selected from a list of courses in the computing field.

\section{AnAlysis AND Discussion}

Following the methodology explained in the previous section, this section focuses on conducting a benchmark comparison for undergraduate degree programs in various computing disciplines offered nationally and internationally.

\section{A. University Type}

We study 161 bachelor programs offered by the selected 36 Saudi and 15 international universities. The Saudi public universities offer 54 programs (33\% of total) while private universities offer 40 programs $(25 \%$ of total). The remaining 67 programs ( $42 \%$ of total) are offered by international universities from 5 countries around the globe, see Table 2 .

\section{B. Program Discipline}

As mentioned in Section III., we follow the 2020 CCR suggested paradigm for undergraduate computing programs, which lists the seven computing disciplines described in Section II. The two disciplines with the largest numbers of programs are computer science (60 programs, $37 \%$ of total), and computer engineering (22 programs, $14 \%$ of total) as depicted in Figure 2. It is 
Table 3: Comparison criteria between computing programs.

\begin{tabular}{|c|c|}
\hline Criteria & Description \\
\hline University Type & $\begin{array}{l}\text { The type of the university offering the program, which maybe } \\
\text { Saudi Private, Saudi Public, or International }\end{array}$ \\
\hline Program Discipline & $\begin{array}{l}\text { The computing discipline of the program based on the } 2020 \\
\text { CCR [3] }\end{array}$ \\
\hline ABET Accreditation & $\begin{array}{l}\text { Whether the program is accredited by the Accreditation Board } \\
\text { for Engineering and Technology (ABET) or not. }\end{array}$ \\
\hline NCAAA Accreditation & $\begin{array}{l}\text { Whether the program is accredited by the National Center for } \\
\text { Academic Accreditation and evaluation (NCAAA) 11 or not. } \\
\text { This applies for Saudi universities only }\end{array}$ \\
\hline Program Duration & The expected number of years to finish the program \\
\hline Number of Units & The number of required units to complete the program \\
\hline Number of Elective Units & The number of computing elective units in the program \\
\hline $\begin{array}{l}\text { Number of Capstone Project } \\
\text { Courses }\end{array}$ & The number of capstone project courses in the program \\
\hline Required Training & $\begin{array}{l}\text { Whether the program requires long cooperative training } \\
\text { (COOP), short internship training, or none. }\end{array}$ \\
\hline Number of Required AI Courses & $\begin{array}{l}\text { The number of Artificial Intelligence (AI) courses that must be } \\
\text { taken in the program }\end{array}$ \\
\hline $\begin{array}{l}\text { Number of Required Security } \\
\text { Courses }\end{array}$ & $\begin{array}{l}\text { The number of security courses that must be taken in the } \\
\text { program }\end{array}$ \\
\hline
\end{tabular}

important to note that, of the programs we study, there are 8 that may not fit under any of the seven 2020 CCR program disciplines. Those programs, such as Artificial Intelligence (AI), are classified as Others. AI is emerging as an independent computing program. Currently, it is being offered by Carnegie Mellon University and the University of Prince Mugrin, among the universities included in this study. It is anticipated that AI will be included in future CCRs. Additionally, there are 25 programs that combine two or more of the computing disciplines in their curricula, e.g., the computer engineering and computer science program offered by the University of Southern California and the computer science and engineering program from the University of California, Los Angeles. These programs are classified as Mixed.

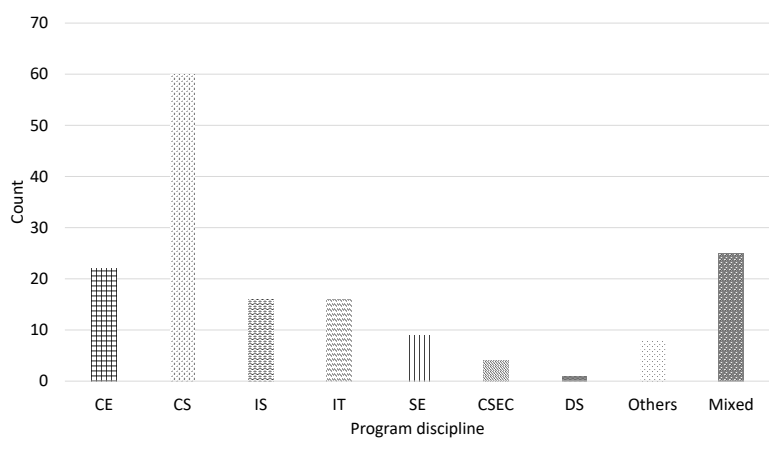

Fig. 2: Number of programs for each program discipline.

Furthermore, when we look into the distribution of programs over the three university types (i.e., public, private, and international), about a half (49\%) of the international programs are CS programs, a percentage that is considerably high compared to the Saudi CS programs (see Figure 3). One reason for the dominance of CS is because it is a fundamental discipline as it covers the theoretical foundations of computing. It is worth pointing out that some may consider CS to cover all aspects of computing [3].

The local Saudi university programs are more uniformly distributed over the different disciplines. In contrast, international universities offer a higher percentage of mixed programs, compared to Saudi universities (24\% vs $10 \%$ ). In addition, there are significantly fewer IS programs offered by the international computing schools. This may be attributed to the fact that IS programs have long been offered by the computing schools in Saudi Arabia while the majority of IS-related programs (often named Management Information Systems, MIS) are offered by the business schools in North America [12, 13. We do not consider the MIS programs in this study.

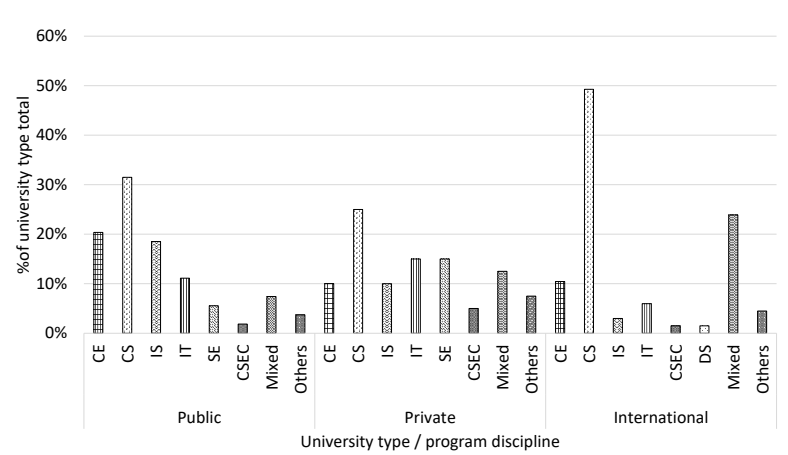

Fig. 3: The distribution of programs by program disciplines and university types. 


\section{Accreditation}

Academic accreditation from ABET is one of the comparative criteria of this study. It is noticeable that ABET academic accreditation is related to the type of university as Figure 4 shows. Less than $15 \%$ of the international and Saudi private university programs are ABET accredited while over $68 \%$ of the public Saudi programs are accredited, as shown in Figure 4. This may be attributed to the fact that many of the Saudi public universities sought, at early stages, to obtain academic accreditation for most undergraduate programs in scientific majors [14]. We find that over half of accredited programs in our study received their first ABET accreditation during the period from 2010 and 2015.

Moreover, the National Commission for Academic Accreditation and Assessment, NCAAA [11] grants academic accreditation to the Saudi academic programs. Of those programs we study, NCAAA has only granted academic accreditation to 14 programs ( $26 \%$ of total public university programs) offered by four public universities, and four other programs (10\% of total private university programs), all are from Effat University.

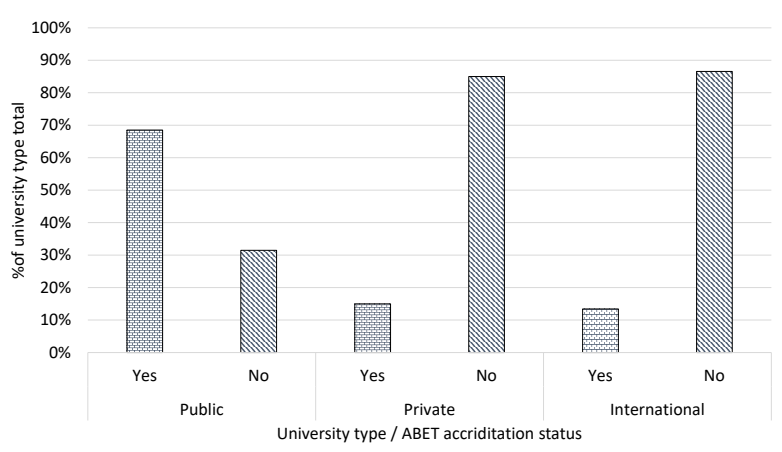

Fig. 4: The distribution of ABET accredited programs by university types.

\section{Program Duration and Required Units}

There is a clear difference between the Saudi- and the internationally- offered programs in terms of the number of required units to complete the programs. It can be seen from Figure 5 that programs offered by the public Saudi universities generally have a higher number of required units (median of 143 units), followed by private Saudi university programs (median of 134 units), while the international university programs are the least in terms of required units (median of 120 units). One main reason for this variance is the number of required major units, both core and elective. International programs require an average of 54 computing units. In contrast, Saudi public and private programs require an average of 83 and 68 computing units, respectively ${ }^{2}$ As a result, over $55 \%$ of the public Saudi university programs are five-year programs, while all the international programs are four or less years, and only $15 \%$ of the Saudi private university programs are five-year programs. For

\footnotetext{
${ }^{2}$ The number of required computing units reaches 116 in the computer science program offered by King Khalid University [15.
}

the public Saudi university programs, it is interesting to see the relationship between the disciplines and their required years of study. Figure 6 shows that $9 \mathrm{CE}$ (out of 11 - over $80 \%$ ) are 5-year programs. CE programs are generally the longest programs (with a median of 156 required units - about 11 more units than the median of the SE programs, the second longest discipline programs). Comparing the 5-year computer engineering with the 4-year computer science programs offered by King Saud University, the computer engineering program has 29 additional units ${ }^{3}$

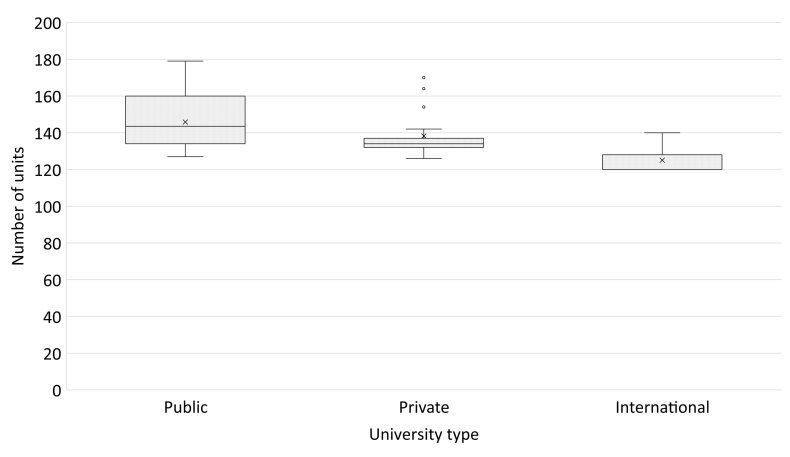

Fig. 5: Number of required units by university type.

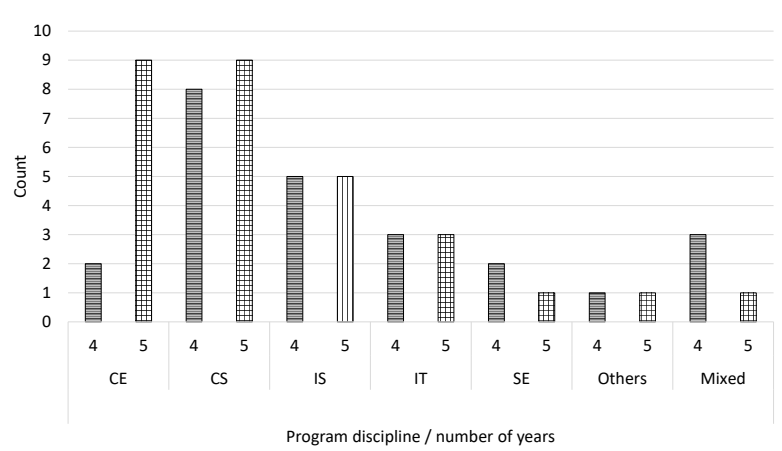

Fig. 6: Counts of 4-year and 5-year programs by programs discipline for the public Saudi universities.

Another interesting observation is the number of elective course units. Offering more elective courses enables students to select their desired courses, tailoring the programs toward their needs. Elective course units are less in local programs compared to their international counterparts. Saudi public and private programs have an average of 10 and 9 elective units, respectively, while international programs have an average of 21 elective units, as seen in Figure 7. One possible reason for this variance is that Saudi universities select to offer more programs across the six computing disciplines, see Figure 3, rather than offering more electives. In contrast, about a half of the international programs are CS programs, which require offering more electives to cover various computing disciplines. Another possible reason to opt for offering

\footnotetext{
${ }^{3}$ These units are mainly electrical engineering courses ( 7 units), additional math courses (6 units), and additional major courses (9 units).
} 
less electives is the associated financial and administrative burdens due to creating and managing more courses.

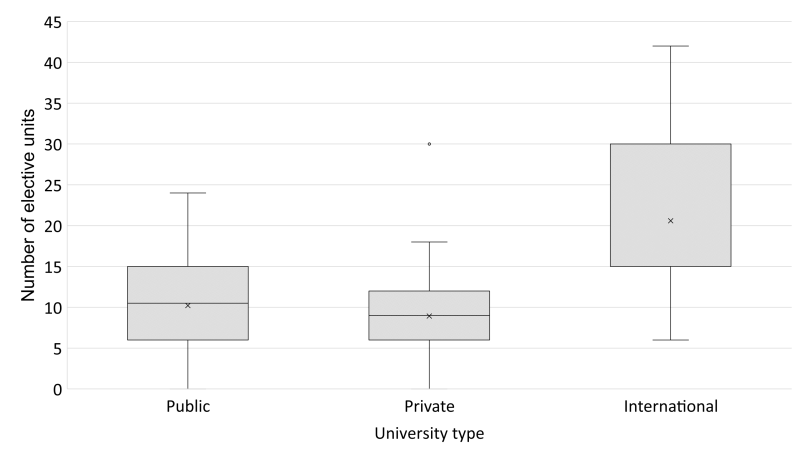

Fig. 7: Number of elective units by university type.

\section{E. Number of Capstone Project Courses}

The number of required capstone project courses is one of the elements that vary across the program types. For example, Figure 8 shows that the majority of programs offered by public universities (91\%) have two capstone project courses, a similar observation is noted for private university programs, but at a lower percentage (68\%), as seen in Figure 8 However, this percentage is much lower $(9 \%)$ for the international university programs, as most programs either require a single capstone project course $(36 \%)$ or do not require any capstone project courses $(55 \%) !^{4}$

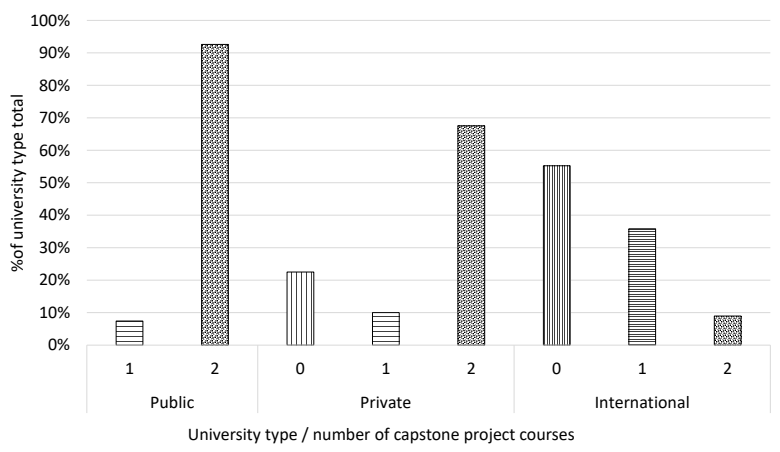

Fig. 8: Percentage of programs with 0,1 , or 2 required capstone project courses by university types.

\section{F. Required Training}

It can be seen from Figure 9 that whether practical training - either long cooperative training (COOP) or short internships - is a requirement by programs we study in this paper. For example, over $75 \%$ of the programs of the international universities do not require students to complete any training credits, while training is required by over $85 \%$ of Saudi university programs, either as COOP training (of approximately six months) or as short internships (ranging typically between two

\footnotetext{
${ }^{4}$ Many universities offer, among the elective courses for senior students, research-based courses that are similar to capstone projects, but the decision of whether to take such courses is left to students.
}

to three months). For both types of Saudi universities (i.e., public and private), the requirement of internships is apparently more common.

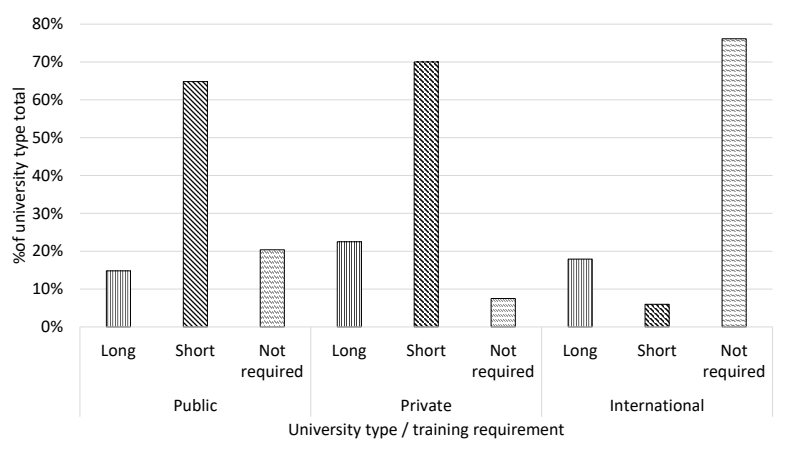

Fig. 9: Percentage of programs with long, short, or not requiring practical training by university types.

\section{G. Number of Required AI and Cybersecurity Courses}

As mentioned, AI and cybersecurity are two fields that are receiving considerable attention in recent years, both nationally and internationally. Most Saudi public university programs (54\%) require AI courses (core or elective) in their curricula, 31 percentage points more than other university programs (both private and international programs have the same percentage of $23 \%$ ). The 2005 and 2020 CCRs suggest that the DS and CS are the two disciplines that intersect with AI the most, a fact observed in our data, e.g., all DS programs and about a half of the CS programs require students to take at least one core AI course. Limited programs falling under other disciplines have core AI courses. Additionally, core cybersecurity courses (one or more) are seen in the curricula of the majority of Saudi public university programs $(81 \%) 5$ compared to $62 \%$ for the Saudi private university and to $13 \%$ for the international university programs. For both AI and cybersecurity, courses are often offered as electives in programs that do not have core AI and cybersecurity courses.

\section{Related Work}

This paper is different from previous work because it focuses on undergraduate computing programs offered by Saudi universities. These programs are reviewed and compared with a set of international programs to understand their commonalities and differences. Locally, AlBaity et al. [17] report their experience of reviewing and designing the IT undergraduate program offered by the College of Computer and Information Sciences at King Saud University to meet ACM/ABET requirements and reflect local and global IT trends.

Various studies, in the literature, were found aiming to differentiate between computing specialties. Researchers' consideration of the computing specialties varied from coarse-grained, to fine-grained beyond and

\footnotetext{
${ }^{5}$ Some cybersecurity programs have over 10 core cybersecurity courses. See 16 as an example.
} 
within computer specialties. The researchers' perspective in the comparison also varied as many focused on how computing programs could be improved while others looked at how to increase the student success and retention and meet the job market needs.

A group of researchers considered the perception of the computing professionals who are involved in the development of software across a variety of industries when suggesting the improvements in different studies. A survey of nearly 300 professionals in one study suggested the required knowledge and skill-sets, and highlighted the value of breadth and flexibility in both soft and hard skill-sets including: the technical skill-sets and the global importance of the critical thinking, problem solving, onthe-job learning, and the ability to work well in crossdisciplinary teams [18]. These findings align with recommendations by the ACM/IEEE task force on computing curricula [2, 3]. Faculties' perspectives and perception on approaches to problem solving, reflective learning and social learning [19] and academia-industry gap in current programs were also considered [20]. Furthermore, other researchers looked at the computing curricula in general and suggested elements that could be considered to improve computing programs. Authors in 21] looked at the effect of the ABET program accreditation on the success of the students and suggested that educational institutions include student-centered measures as the program accreditation failed to show notable improvement in the students' success. Moreover, authors in 22 studied the effect of using open-source technologies to build redundant virtual servers that enable infrastructure stability and resiliency. Another study [23] proposed a model that uses the Bildung concept which should contribute to increasing the relevance and value of the educational program content. The model deploys the Bildung concept to suggest a computing education framework about one-self by understanding what defines human beings, their role in life and society; and self-determination contribution. It emphasises on the importance of building a curriculum centered around the mutual interaction between a human and a digital artefact. Eventually, however, the above group's main focus was on the individual learning outcomes in relation to hard and soft skill-sets gained without distinguishing between the different specialties.

The other group of researchers focused on specific elements beyond or within the computing specialties. Researchers in 24 focused on the undergraduate research programs in Computer Science (CS) to study the early benefits of undergraduate research. While in [25], the researchers focused on gender-oriented success rate in the computing specialties. This study suggested that the differences between male and female students are not fundamental, as performance differences only occur in specific circumstances, and in both directions. Another set of studies investigated the introduction of some concepts to improve current computing academic programs and develop the students' skill-sets. This introduction could happen through the courses or the capstone projects within the computing specialties such as Quantum com- puting [26], web science [27], and Internet of Thing [28]. The researchers within this group fall short in providing a holistic overview of the computing specialties but rather focus on a fine-grained element beyond or within the specialty.

The final group of researchers focus on computing specialty specifics as defined in this research. The CCRs are an initiative launched jointly by several professional computing societies including the Association for Computing Machinery (ACM) and the IEEE Computer Society (IEEE-CS). The aim of the project is to summarize and synthesize the current state of curricular guidelines for academic programs that grant baccalaureate-level degrees in computing as well as propose a vision for future curricular guidelines [3, 29, 30. The very first publication of the computing curricula was in 1968 [31. Since then and as the field of computing has grown and diversified, the curricular recommendations, and their specialties have evolved to adapt with this growth. Volumes are updated regularly for the specializations with the aim of keeping computing curricula modern and relevant. The 2005 CCR 2 consists of an overview document, and model curricula for the different specialties introduced earlier such as: Computer Engineering (CE2004), Information Systems (IS2002), and Software Engineering (SE2004) in addition to Computer Science (CS2001). In 2008, the first Information Technologies CCR (IT2008) was published. Cybersecurity CSE 2017 is the latest volume of the IEEE-CS/ACM joint task force on CCR series. At the August 2017 ACM Education Council meeting, a task force was formed to explore a process to add to the broad, interdisciplinary conversation on data science, with an articulation of the role of computing discipline-specific contributions to this emerging field. The 2020 CCR consists of a task force of more than forty academic, industry, and government representatives representing seventeen countries from six continents. The 2020 CCR provides a vision for the future of computing, to produce a comprehensive report that contrasts curricular guidelines, and to contextualize those guidelines within a landscape of computing education based on a framework of competency-based educational principles. Competency in this project considers knowledge, skills, and dispositions.

\section{Conclusion and Future Work}

Results show that computer science dominates undergraduate computing programs locally (29\% of local programs) and internationally (49\% of international programs). Local Saudi university programs are more uniformly distributed over the different disciplines. In contrast, international universities offer considerably more mixed programs, $24 \%$ compared to $10 \%$. It becomes crucial to assess the value of offering undergraduate computing programs in the defined disciplines by the 2020 CCR [3] or a mix of them. One future direction of this study is to evaluate how these computing disciplines are perceived from the job market point of view. This includes collecting data about graduates holding degrees 
of various computing disciplines to evaluate if they were preferred for certain jobs or had been recruited differently. Furthermore, it is notable that programs offered by Saudi universities, especially public, have more units, extending the study duration. These programs have significantly more computing units compared to international programs, see Section IV. for details, a note that may need to be considered for future program plan updates.

\section{ACKNOWLEDGMENT}

To be completed in the camera-ready version.

\section{REFERENCES}

[1] E. L. Alvarez-Aros and C. A. Bernal-Torres, "Technological Competitiveness and Emerging Technologies in Industry 4.0 and Industry 5.0," Anais da Academia Brasileira de Ciências, vol. 93, 2021.

[2] R. Shackelford, A. McGettrick, R. Sloan, H. Topi, G. Davies, R. Kamali, J. Cross, J. Impagliazzo, R. LeBlanc, and B. Lunt, "Computing Curricula 2005: The Overview Report," in Proceedings of the 37th SIGCSE Technical Symposium on Computer Science Education, ser. SIGCSE '06. ACM, 2006, p. $456-457$.

[3] A. Clear, A. S. Parrish, J. Impagliazzo, and M. Zhang, "Computing Curricula 2020: Introduction and Community Engagement," in Proceedings of the 50th ACM Technical Symposium on Computer Science Education, ser. SIGCSE '19. New York, NY, USA: Association for Computing Machinery, 2019, p. 653-654. [Online]. Available: https://doi.org/10.1145/3287324.3287517

[4] "Demand for Saudi ICT Skills Set to Intensify," https://www.ameinfo. com/industry/tech-and-mobility/ demand-for-saudi-ict-skills-set-to-intensify, (Accessed on $02 / 22 / 2021$ ).

[5] M. Loukides, What is Data Science? " O'Reilly Media, Inc.", 2011.

[6] "Shanghairanking's ranking of academic subjects 2020 - computer science and engineering," http://www.shanghairanking. com/Shanghairanking-Subject-Rankings/ computer-science-engineering.html, (Accessed on $02 / 13 / 2021)$.

[7] "National Cybersecurity Authority," https: //www.nca.gov.sa/en/index.html, (Accessed on $02 / 16 / 2021)$.

[8] "Sdaia," https://sdaia.gov.sa/?Lang=en, (Accessed on $02 / 16 / 2021)$.

[9] O. Hassan, "Artificial Intelligence, Neom and Saudi Arabia's Economic Diversification from Oil and Gas," The Political Quarterly, vol. 91, no. 1, pp. 222-227, 2020.

[10] F. Dalichow, "A Comparative Study of Academic Credit Systems in an International Context," Journal of Studies in International Education, vol. 1, no. 2, pp. 21-32, 1997.
[11] "NCAAA," https://etec.gov.sa/en/About/ Centers/Pages/Accreditation.aspx on $02 / 13 / 2021)$.

[12] D. S. Hussain and K. M. Hussain, Information Systems for Business. Prentice Hall, 1991.

[13] I. C. Ehie, "Developing a Management Information Systems (MIS) Curriculum: Perspectives from MIS Practitioners," Journal of Education for Business, vol. 77, no. 3, pp. 151-158, 2002.

[14] S. A. Al-Yahya and M. A. Abdel-Halim, "A Successful Experience of ABET Accreditation of an Electrical Engineering Program," IEEE Transactions on Education, vol. 56, no. 2, pp. 165-173, 2012.

[15] "Study Plan — College of Computer Science," https://cs.kku.edu.sa/en/csstudyplan, (Accessed on 02/13/2021).

[16] "Bachelor of Science in Cyber Security and Digital Forensics (CYS) - Imam Abdulrahman Bin Faisal University," https://www.iau.edu.sa/en/colleges/ college-of-computer-science-and-informationtechnology/programs/ bachelor-of-science-in-cyber-security-and- $\backslash$ digital-forensics-cys, (Accessed on 02/13/2021).

[17] H. Al-Baity, D. H. Alsaeed, S. Bayoumi, N. AlTwairesh, and H. Al-Khalifa, "Rejuvenation of the IT Program at King Saud University: A Change Reflecting Local and Global IT Trends," in Proceedings of the 19th Annual SIG Conference on Information Technology Education, ser. SIGITE' 18. New York, NY, USA: Association for Computing Machinery, 2018, p. 129-134. [Online]. Available: https://doi.org/10.1145/3241815.3241866

[18] M. Exter, S. Caskurlu, and T. Fernandez, "Comparing Computing Professionals' Perceptions of Importance of Skills and Knowledge on the Job and Coverage in Undergraduate Experiences," ACM Transactions on Computing Education, 2018.

[19] S. Mason, "Examining Faculty Perceptions and Approaches to Problem Solving, Reflective Learning and Social Learning in a Computing Education Program: An Exploratory Case Study," in Proceedings of the 20th Annual SIG Conference on Information Technology Education, 2019.

[20] S. Valstar, S. Krause-Levy, A. Macedo, W. G. Griswold, and L. Porter, "Faculty Views on the Goals of an Undergraduate CS Education and the AcademiaIndustry Gap," in Proceedings of the 51st ACM Technical Symposium on Computer Science Education, 2020.

[21] P. Basavaraj and I. Garibay, "Enhancing the Program Quality and College-Level Success Metrics of an IT Program at a Large Public University," in Proceedings of the 20th Annual SIG Conference on Information Technology Education, 2019, pp. 16-21.

[22] C. Stephenson, A. D. Miller, C. Alvarado, L. Barker, V. Barr, T. Camp, C. Frieze, C. Lewis, E. C. Mindell, L. Limbird et al., Retention in Computer Science Undergraduate Programs in the US: Data challenges and Promising Interventions. ACM, 2018. 
[23] C. Schulte and L. Budde, "A Framework for Computing Education: Hybrid Interaction System: The Need for a Bigger Picture in Computing Education," in Proceedings of the 18th Koli Calling International Conference on Computing Education Research, ser. Koli Calling '18. New York, NY, USA: Association for Computing Machinery, 2018. [Online]. Available: https://doi-org.sdl.idm.oclc. org/10.1145/3279720.3279733

[24] C. Alvarado, S. Villazon, and B. Tamer, "Evaluating a Scalable Program for Undergraduate CS Research," in Proceedings of the 2019 ACM Conference on International Computing Education Research, 2019, pp. 269-277.

[25] J. McBroom, I. Koprinska, and K. Yacef, "Understanding Gender Differences to Improve Equity in Computer Programming Education," in Proceedings of the Twenty-Second Australasian Computing Education Conference, 2020.

[26] N. Kiefl and G. Hagel, "Software Engineering Education of Classical Computing vs. Quantum Computing: A Competency-Centric Approach," in Proceedings of the 4 th European Conference on Software Engineering Education, 2020, pp. 27-31.

[27] E. Coskun and S. White, "Web Science: Mapping the Curriculum," in Proceedings of the 2017 ACM on Web Science Conference, 2017, pp. 241-245.

[28] B. Burd, L. Barker, F. A. F. Pérez, I. Russell, B. Siever, L. Tudor, M. McCarthy, and I. Pollock, "The Internet of Things in Undergraduate Computer and Information Science Education: Exploring Curricula and Pedagogy," in Proceedings Companion of the 23rd Annual ACM Conference on Innovation and Technology in Computer Science Education, 2018.

[29] J. Impagliazzo and A. N. Pears, "The CC2020 Project-Computing Curricula Guidelines for the 2020s," in 2018 IEEE Global Engineering Education Conference (EDUCON). IEEE, 2018, pp. 20212024.

[30] J. Impagliazzo, B. A. Becker, A. Clear, E. CuadrosVargas, X. Du, and A. Vichare, "Perspectives on Global Bachelor Computing Education," in Proceedings of the ACM Conference on Global Computing Education, 2019, pp. 127-128.

[31] W. Atchison, "ACM Curriculum Committee on Computer Science. Curriculum 68: Recommendations for Academic programs in Computer Science," Comm. ACM, vol. 11, no. 3, pp. 151-197, 1968.

Contribution of individual authors to the creation of a scientific article (ghostwriting policy)

Yazeed Alabdulkarim carried out the data collection, and organization of work, and the classification of program disciplines.

Mohammed Almukaynizi has produced the aggregate analysis and figures of Section IV.

Marwan Almaymoni and Abdulaziz Alhadlag have organized and extracted data from the university websites into spreadsheets.

Hessah Alsalamah was responsible for the design of the criteria for the comparison and the selection of universities.

Shada Alsalamah was responsible for Section V.

\section{Creative Commons Attribution License 4.0 (Attribution 4.0 International, CC BY 4.0)}

This article is published under the terms of the Creative Commons Attribution License 4.0 https://creativecommons.org/licenses/by/4.0/deed.en_US 